endeavours to explain at least the gist of its development, a development to which he himself made important contributions. Has he succeeded? I am not sure. That the treatment of the mathematics is rather sketchy does not matter for the professional physicist: one can always turn to Inward Bound and, if one wants to become a real expert, from there to one of several good textbooks. But has Pais given nonphysicists an inkling of the reaction of physicists to the sensational news of charge parity violation? Can he convince authorities that it is worth spending thousands of millions to create a few extremely short-lived particles? Perhaps that is asking too much.

No book is perfect. Although Pais is on the whole very readable and both instructive and entertaining, he is sometimes a bit long-winded. Several sections, in particular those dealing with travel, could do with pruning, and some duplication might have been avoided. Pais himself recommends an index of subjects, but does not follow his own advice. But these minor shortcomings in no way detract from the value of this impressive book.

H. B. G. Casimir is at De Zegge 7, 5591 TT Heeze, The Netherlands.

\section{Our flexible friends}

\section{Cells, Embryos and Evolution: Towards a Cellular and Developmental Understanding of Phenotypic Variation and Evolutionary Adaptability}

by John Gerhart and Marc Kirschner

Blackwell Science: 1997. Pp. 642.

$\mathfrak{£} 29.50, \$ 64.95$

\section{J.M.W.Slack}

Every biologist has heard of Darwin's finches and knows that the shape of the beak may evolve differently depending on the food source. But how many ways are there to change a beak? Is the range of possible beaks limited by developmental constraints? Are modern birds better at changing their beaks than their remote forebears? These questions are posed in the preface to Cells, Embryos and Evolution to emphasize that now is the time to apply our newly found molecular understanding of development to find out what really happened in evolution.

John Gerhart and Marc Kirschner are distinguished experts in cell and developmental biology. As might be expected, they paint a mighty canvas and fill it with good things. Much of their text is devoted to a detailed explanation of the main developmental processes in vertebrates and insects, rather less to some important themes in cell biology, and several chapters to an investigation of how the organization of developmental systems has facilitated

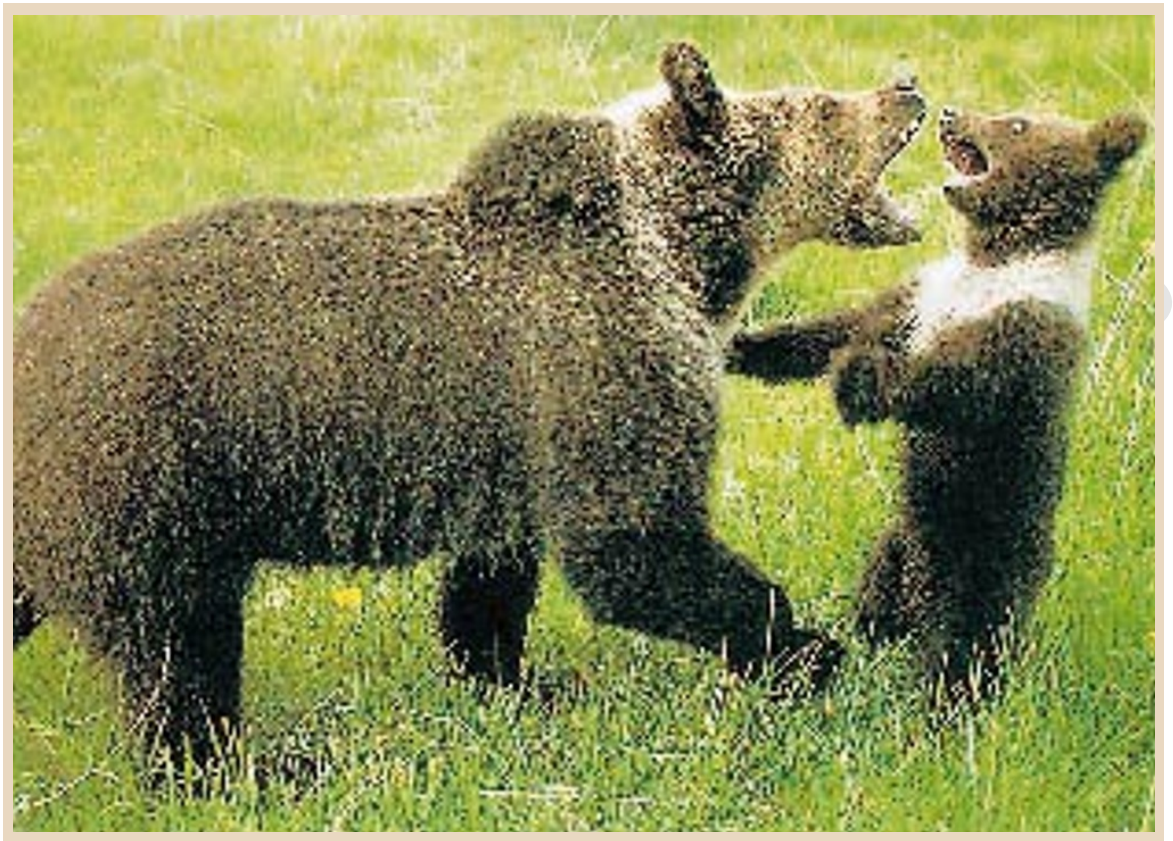

\title{
Bear essentials
}

Conventional wisdom says you should never come between a mother bear and her cubs. Inadvertently, Erwin A. Bauer did just that when he fell asleep on a hiking trail in Grand Teton National Park in Wyoming. But the bears ignored him and he survived to recount the tale in the introduction to his book, Bears: Behavior, Ecology, Conservation (Voyageur Press, \$35).

the evolution of morphological novelty.

Their grand theme is that the developmental systems of metazoa show "flexibility and robustness", characteristics that may enable mutations to produce significant changes in morphology without always being disadvantageous. The elements of such a system are things such as parallel pathways, weak rather than strong regulatory connections, or competitive and exploratory mechanisms rather than fully determined ones. There may be a progressive increase in 'evolvability' of this kind over evolutionary time. There is no doubt that the developmental mechanisms of vertebrates and insects, which are the two best understood animal groups, show these features, albeit in rather different ways.

But, if we are to ascribe their success in producing many varied morphologies to such characteristics, then we must ask whether other groups that have failed to produce such variety have a developmental system that is demonstrably more rigid. This could possibly be argued of the nematodes, whose morphological diversity as a phylum does not seem to match that of the arthropods or chordates. Early studies of Caenorhabditis elegans did emphasize its rigid cell lineage, but the more the nematode has been studied the less 'hard wiring' of events has been evident and the more signalling processes have been discovered, which would count as "flexible" to Gerhart and Kirschner.
This is the latest in a series of popular books from Voyageur exploring the world of North American bears. In the above picture, one of many fine photos in the book by Erwin and Peggy Bauer, a mother grizzly disciplines a surprised cub that has been wandering too far away. The author gives tips for capturing these elusive creatures on film.

Things are even less clear when we encounter the 'priapulid problem'. The priapulids, named after the eponymous Priapus with his large male generative organ, are an entire phylum containing only 17 species that seem to have changed hardly at all since their appearance in the Middle Cambrian. We have no idea whether they have stayed the same because their developmental systems are inherently less evolvable than more glamorous phyla, or whether there has simply been little selective pressure for diversification because conditions down in the marine mud have not changed much in the past 530 million years.

The book tends to play down the importance of 'constraints', which are the usual concern of developmental biologists. It was at one time supposed that changing almost anything in early development would be impossible because of the knock-on effects on later stages. But this view has tended to moderate as people have become more familiar with the wide range of early adaptations to different reproductive lifestyles. It is now recognized that the stage of maximum similarity between members of a taxon is not the earliest embryonic stage, but the middle stage. This is often called the 'phylotypic' stage, and receives many mentions in the book. But the authors are a little coy about committing themselves to the existence of any phylotypic stages other than the familiar pharyngula of the vertebrates and extended germ band of the insects. 
They tentatively suggest that a "commaform" nematode might be phylotypic, but neglect other possible candidates such as the veliger larva of gastropods, or an early segmenting stage of an annelid worm. In accordance with their general case they argue that the conservation of the phylotypic stage is due to its flexibility and robustness, and do not seriously consider the alternative view that it has stayed the same because selective pressures are at a minimum in the middle stages of development.

The most spectacular achievement of molecular developmental biology has been the discovery of long-range homologies between animal groups in terms of things such as the molecular basis of anteroposterior and dorsoventral patterning. These discoveries enable us to reconstruct long dead ancestors in a way that would have been unthinkable a few years ago.

Gerhart and Kirschner use these data to argue that the stem metazoan was a "roundish flatworm" that flourished below the surface of the Vendian biomat. This organism had Hox genes specifying the anteroposterior pattern; emx/otx genes to code for the head; chordin/Bmp-4 signalling for the dorsoventral organization; pax6 doing the photoreceptor; $m y o D$ doing the muscle and so on. It is tempting to imagine this robust ancestor of ours as being one of the creatures that created the fossilized burrows in the Vendian and Cambrian sediments, some of which can still apparently be found complete with fossilized faeces.

The best parts of the book are those that use information from molecular biology to tell us what actually happened in evolution. For example, milk is a novelty created by the mammals. But the lactose synthetase consists of two components: a galactosyl transferase that was formerly used to assemble glycoprotein carbohydrate chains; and $\alpha$-lactalbumin, which is a modified version of lysozyme. Similar molecular insight is applied to other examples, such as the origin of myelin, of intermediate filaments, and oflens crystallins.

\section{New in paperback}

\section{The Lives to Come: The \\ Genetic Revolution and Human \\ Possibilities}

by Philip Kitcher

Penguin, £8.99

"Stimulating, informative and courageous.... Kitcher's arguments are always compassionate, always ingenious and always worth pursuing", wrote John Harris in a review in Nature 380, 591 (1996).

\section{The Value of Life: Biological Diversity} and Human Society

by Stephen R. Kellert

Island Press, $\$ 16.95$
The lens serves to introduce what must be the most amazing animal in the book. The cubomedusoid jellyfish, Tripedalia, apparently has image-forming eyes but no central nervous system to process or interpret the image. Creationists used to tell us that the image-forming eye could not possibly have evolved by chance because of all the coordinated changes that would simultaneously have been required in the brain. So I am left unsure whether Tripedalia represents real evidence against the existence of God, or just flexible robustness run riot.

The book is not designed for undergraduate teaching as it lacks the basic descriptive embryology on which to hang the molecular story. It is well written but fairly long and the intended market is presumably graduate courses for students already familiar with developmental mechanisms who want to explore their implications for evolution. It is just the job for students who want to make their debating skills in molecular evolution more robustly flexible.

J. M. W. Slack is in the Department of Biology and Biochemistry, University of Bath, Bath BA2 7AY, UK.

\section{Earthquakes and elephants}

\section{Fieldwork: A Geologist's Memoir of the Kalahari}

by Christopher Scholz

Princeton University Press: 1997. Pp. 190.

$\$ 24.95, £ 19.95$

\section{Keith Cox}

In 1974 Christopher Scholz and his team carried out a survey of seismicity in the Kalahari Desert in southern Africa, at the request of the United Nations Food and Agriculture Organization. They achieved some decent scientific results, but also had a whale of a time, with experiences varying from the comic through the

"Immensely stimulating, tending to inspire new questions with every one it answers". Thomas Lovejoy, Nature 382, 594 (1996).

\section{Our Evolving Universe}

by Malcolm S. Longair

Cambridge University Press, $£ 14.95$

"A beautifully produced book, in an oversize format, with an elegant typographical design, clear diagrams and many colour illustrations... the text is unflinchingly direct and accurate.... Its content is that of a first-rate introductory course". William Press, Nature 382, 220 (1996). awe-inspiring to the downright frightening.

Few Earth scientists write anything in the style of their life's memoirs, so this book is doubly welcome. It should appeal to a wide variety of readers, whether fieldworkers or not. The science is accessibly laid out and richly embroidered with tales of the bush.

The scientific problem that the team tackled was to discover whether there is an active extension of the East African rift system into Botswana. Is this the tip of the system propagating itself southward? The question is potentially important because when a fault, such as that forming the edge of a rift, moves and generates an earthquake, there is a change of elevation along the line where the fault-plane reaches the surface. The Kalahari is very flat and the drainage system is in a delicate balance, around the Okavango delta, for example. A large change in the drainage pattern could easily be induced by only a minor movement, and lead to profound ecological consequences.

Botswana is not noted for big earthquakes, but any seismically active area produces many small earthquakes. So the survey had to deal with micro-earthquakes which, predictably, would turn up in sufficient numbers during the few months spent in the field. The technique is to install an array of three or more seismometers with recording devices, leave them for a day or several days, and then see what you have caught. Then the array is moved somewhere else, and so on.

But much of the Kalahari is covered with more-or-less unconsolidated sand, about the worst possible material through which to try to detect micro-earthquakes. As a result, much time had to be devoted to the search for areas of solid bedrock. This travelling about, setting up camp, overcoming obstacles, coping with the wildlife and, not least, confronting officialdom, forms the substance of the book. It is rich in accounts of the incidents that such a mode of life throws up.

It was necessary, for example, to set up camp in thick bush half a mile from the only watering hole for miles. The only clear strip of bush to camp on turned out to be the main route used by elephants at night on their way to have a drink. Add a few thousand nearby antelopes, lions, hyenas and so on, and the night becomes alarmingly noisy.

In the end, the party managed to observe a sufficient number of micro-earthquakes to confirm their hypothesis. The author comments that when the work was published, it did not cause a great stir, but he regards it as an honest and useful job well done.

Although much of the book is devoted to the sheer joy of life in the bush (and its per- 